\title{
NUMERICAL ANALYSIS OF INFLUENCE OF ENGINEERING CONSTRUCTION IN THE AREA OF PLACING FUEL STORAGE TANKS ON THEIR HEAT LOSS
}

\author{
V. Yu. Polovnikov ${ }^{1, *}, F$. T. Makhsutbek ${ }^{1}$, Zh. F. Ozhikenova ${ }^{1}$, and $I$. K. Zharova ${ }^{2}$ \\ ${ }^{1}$ National Research Tomsk Polytechnic University, 634050 Tomsk, Russia \\ ${ }^{2}$ Scientific Research Institute of Applied Mathematics and Mechanics, 634050 Tomsk, Russia
}

\begin{abstract}
This paper describes the numerical modeling of heat transfer in the area placing of the tank for storage fuel of thermal power plant and boiler with the influence of engineering construction. We have established that the presence of engineering structures in the area of placing of the tank for storage fuel of thermal power plant and boiler have little effect on the change of heat loss.
\end{abstract}

\section{INTRODUCTION}

The research of thermal modes of different objects (a residential building [1], a hot water pipes [2], a fuel storage tank et al.) is an important problem.

Currently, the method of calculation and design of a fuel storage tank does not take full account of all processes in a tank, that occur during the preparation of a fuel oil for combustion.

One of the most promising approaches to research of different equipment is the use of a computer programs. They take into account various effects and processes in the system of heat transfer.

The objective is the mathematical modeling of the thermal loss of fuel storage tank and numerical analysis of thermal conditions of the tank.

\section{Problem statement}

We consider a typical vertical cylindrical steel underground tank. Figure 1 shows a schematic representation of the field solution of the problem. For the domain under consideration (fig. 1) we solve a 2D linear and stationary problem of heat transfer in conditions of thawing of the soil.

Formulating the problem, we used the following assumptions:

1. The heat transfer processes in the internal and the external environment are disregarded.

\footnotetext{
* Corresponding author: polov@tpu.ru
} 
2. Thermophysical characteristics of materials used in the analysis are constant and known values.

3. There is an ideal thermal contact conditions at the boundaries.

4. The heat in the decision domain (fig. 1) is transferred only by conduction.

The listed assumptions, on the one hand, do not impose constrains of principle on the physical model of the system (fig. 1), but, on the other hand, allow one to simplify in a certain manner the algorithm and method for solving the posed problem.

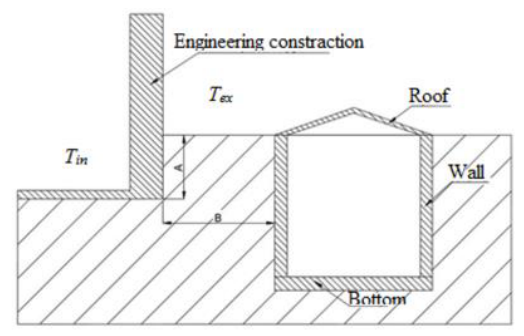

Fig. 1. Schematic representation of the field solution of the problem.

\section{Mathematical model}

The processes of heat transfer to the object under consideration (fig. 1) will be described by the following equation:

$$
\begin{aligned}
& \nabla^{2} T_{\text {ins }}=0 ; \\
& \nabla^{2} T_{\mathrm{g}}=0 \\
& \nabla^{2} T_{\mathrm{f}}=0 ; \\
& T_{\mathrm{ins}, 1}=T_{\mathrm{oil}}=\mathrm{const} \text {; } \\
& \lambda_{\text {ins }} \operatorname{grad}\left(T_{\text {ins }, 2}\right)=\lambda_{\mathrm{g}} \operatorname{grad}\left(T_{\mathrm{g}, 2}\right) ; T_{\text {ins }, 2}=T_{\mathrm{g}, 2} ; \\
& \lambda_{\mathrm{g}} \operatorname{grad}\left(T_{\mathrm{g}, 3}\right)=\lambda_{\mathrm{f}} \operatorname{grad}\left(T_{\mathrm{f}, 3}\right) ; T_{\mathrm{g}, 3}=T_{\mathrm{f}, 3} ; \\
& -\lambda_{\mathrm{g}} \operatorname{grad}\left(T_{\mathrm{g}, 4}\right)=\alpha\left(T_{\mathrm{g}, 4}-T_{\mathrm{ex}}\right) \\
& -\lambda_{\mathrm{f}} \operatorname{grad}\left(T_{\mathrm{f}, 5}\right)=\alpha\left(T_{\mathrm{f}, 5}-T_{\mathrm{ex}}\right) ; \\
& -\lambda_{\mathrm{f}} \operatorname{grad}\left(T_{\mathrm{f}, 6}\right)=\alpha\left(T_{\mathrm{f}, 6}-T_{\mathrm{in}}\right) ; \\
& -\lambda_{\mathrm{f}} \operatorname{grad}\left(T_{\mathrm{f}, 7}\right)=\alpha\left(T_{\mathrm{f}, 7}-T_{\mathrm{in}}\right) ; \\
& \operatorname{grad}\left(T_{\mathrm{g}}\right)=0, x_{\rightarrow \pm \infty}, y_{\rightarrow-\infty} \\
& \operatorname{grad}\left(T_{\mathrm{f}}\right)=0, x_{\rightarrow \pm \infty}, y_{\rightarrow+\infty} .
\end{aligned}
$$




\section{Method of solution and Initial data}

The system of equations (1)-(8) was solved by the finite element method [3, 4], using the Galerkin approximation [5]. The investigations were carried out on a nonuniform finiteelement mesh. The number of elements was chosen from conditions of convergence of solution, the mesh was made denser by the Delaunay method [5].

In spite of the fact that in statement of the problem it was assumed to use an infinite-size domain (expressions (11) and (12)), in the numerical analysis of heat loss we used a finite size of calculation domain. The sizes of the calculation domain were chosen on the basis of a series of preliminary numerical experiments in such a manner that the relative change of the temperature gradients at the domain boundary does not exceed $0.5 \%$.

The analysis was carried out for a vertical steel tank with the thermal insulation of mineral wool $(50 \mathrm{~mm}$ thick $)$. The temperature of an oil was $T_{\mathrm{oil}}=353^{\circ} \mathrm{K}$. The ambient temperature $T_{\mathrm{ex}}$ taken equal to the average air temperature for the heating period in the city of Tomsk. The air temperature inside the engineering structure was equal to $T_{\text {in }}=293.15 \mathrm{~K}$. The coefficients of heat transfer in all variants of the numerical analysis were $\alpha=15 \mathrm{~W} /\left(\mathrm{m}^{2} \cdot \mathrm{K}\right)$. The change of temperature in depth of soil is 3.6 degrees per 100 meters. The distance from the external tank insulation to the basement was $\mathrm{B}=20 \mathrm{~m}$, and the deepening of the foundation was $\mathrm{A}=2 \mathrm{~m}$ (fig. 1).

Table 1 contains values $[2,4]$ of thermophysical characteristics, which were used in the numerical investigations of thermal conditions of the system under consideration (fig. 1).

Table 1. Thermal properties of materials.

\begin{tabular}{|c|c|c|c|}
\hline Material & $\begin{array}{c}\text { Density, } \\
{\left[\mathbf{k g} / \mathbf{m}^{\mathbf{3}}\right]}\end{array}$ & $\begin{array}{c}\text { Thermal conductivity, } \\
[\mathbf{W} / \mathbf{( m \cdot K})]\end{array}$ & $\begin{array}{c}\text { Heat capacity, } \\
[\mathbf{J} / \mathbf{( k g} \cdot \mathbf{K})]\end{array}$ \\
\hline Mineral wool & 150 & 0.046 & 840 \\
\hline Reinforced concrete & 2200 & 1.54 & 887 \\
\hline Ground & 1835 & 1.42 & 1155 \\
\hline
\end{tabular}

\section{Results of numerical simulation}

The main results of numerical modeling of thermal conditions of the system under consideration (fig. 1) are listed in Table 2, 3 and in figures 2, 3.

Table 2 lists the results of numerical experiments of the heat loss of a vertical cylindrical steel underground tank $\left(Q_{1}\right.$ is the heat loss without engineering construction and $Q_{2}$ is the heat loss with considering engineering construction).

Validity and reliability of the obtained results follow from tests of the methods for convergence and stability of solutions on multiple meshes, fulfillment of the energy balance conditions at boundaries of the calculation domain. The relative calculation error in all versions of the numerical analysis did not exceed $0.5 \%$, which is acceptable for investigations of thermal conditions of the system under consideration (fig. 1).

Figures 2 and 3 show the typical temperature fields in the area of storage tanks for fuel thermal power plants and boiler plants.

Numerical analysis results indicate that the presence of thawing of soil in the container placement area for the storage of fuel thermal power plants and boiler houses does not lead to significant changes in the thermal regime of the object.

Figures 2 and 3 show the typical temperature fields in the area of storage tanks for fuel thermal power plants and boiler plants, taking into account the thawing of sandy and clay soil. 
Table 2. The results of heat loss underground tank without taking a fixed ground temperature.

\begin{tabular}{|c|c|c|c|c|}
\hline Month & $\boldsymbol{T}_{\text {ex }},\left[{ }^{\circ} \mathbf{C}\right]$ & $\boldsymbol{Q}_{1},[\mathbf{W}]$ & $\boldsymbol{Q}_{2},[\mathbf{W}]$ & $\left|\left(\boldsymbol{Q}_{1}-\boldsymbol{Q}_{2}\right) / \boldsymbol{Q}_{\mathbf{1}}\right| \mathbf{1 0 0} \%$ \\
\hline September & +9.2 & 6519.76 & 6542.28 & 0.34 \\
\hline October & +0.9 & 7666.57 & 7704.85 & 0.50 \\
\hline November & -10.4 & 9228.60 & 9310.08 & 0.88 \\
\hline December & -17.5 & 10233.07 & 10349.46 & 1.12 \\
\hline January & -19.2 & 10449.10 & 10587.58 & 1.31 \\
\hline February & -16.7 & 10121.49 & 10214.96 & 0.92 \\
\hline March & -10.1 & 9182.77 & 9245.62 & 0.68 \\
\hline April & -0.1 & 7782.53 & 7822.48 & 0.51 \\
\hline May & +8.6 & 6603.88 & 6648.76 & 0.68 \\
\hline June & +15.3 & 5665.41 & 5687.85 & 0.39 \\
\hline
\end{tabular}

Table 3. The results of heat loss underground tank based on a fixed soil temperature.

\begin{tabular}{|c|c|c|c|c|}
\hline Month & $\left.\boldsymbol{T}_{\mathbf{e x}},{ }^{\circ} \mathbf{C}\right]$ & $\boldsymbol{Q}_{1},[\mathbf{W}]$ & $\boldsymbol{Q}_{2},[\mathbf{W}]$ & $\left|\left(\boldsymbol{Q}_{\mathbf{1}}-\boldsymbol{Q}_{2}\right) / \boldsymbol{Q}_{\mathbf{1}}\right| \mathbf{1 0 0} \mathbf{0}$ \\
\hline September & +9.2 & 6278.26 & 6323.88 & 0.72 \\
\hline October & +0.9 & 7507.07 & 7574.23 & 0.89 \\
\hline November & -10.4 & 9103.06 & 9185.61 & 0.90 \\
\hline December & -17.5 & 10106.08 & 10214.12 & 1.06 \\
\hline January & -19.2 & 10346.24 & 10519.14 & 1.64 \\
\hline February & -16.7 & 9992.97 & 10102.27 & 1.08 \\
\hline March & -10.1 & 9060.87 & 9157.06 & 1.05 \\
\hline April & -0.1 & 7648.47 & 7714.04 & 0.85 \\
\hline May & +8.6 & 6419.66 & 6469.05 & 0.76 \\
\hline June & +15.3 & 5473.19 & 5504.81 & 0.57 \\
\hline
\end{tabular}

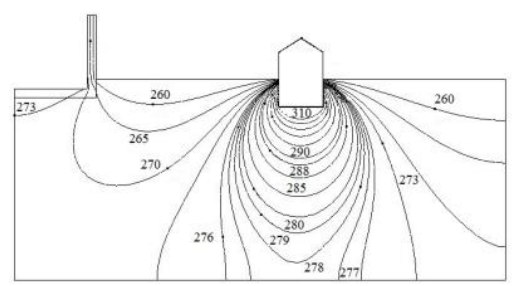

Fig. 2. Typical temperature field in the zone of the storage tanks for fuel thermal power plants and boiler at ambient temperature $-40^{\circ} \mathrm{C}$, taking into account the impact of engineering structures.

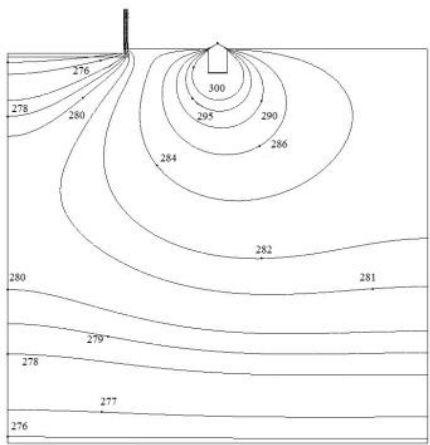

Fig. 3. Typical temperature field in the zone of the storage tanks for fuel thermal power plants and boiler at ambient temperature $-40{ }^{\circ} \mathrm{C}$, taking into account the impact of engineering structures, consider a fixed temperature of the soil. 


\section{Conclusion}

Numerical analysis of heat loss of storage tanks for fuel thermal power plants and boiler plants (Table 2, 3 and Fig. 2,3) indicate that the presence of engineering structures in the area of their distribution have little effect on the change of heat loss, so you can ignore this indication. The maximum deviation in the calculations (table 2 and 3 ) is not more than $2 \%$. Therefore the influence of engineering structures in the area of storage tanks for fuels, power plants and boilers can be reasonably neglected.

The result of numerical analysis of heat loss of storage tanks for fuels, power plants and boilers it is possible to say that the introduction of a fixed temperature on the lower boundary of the solution has little effect on the changes of heat loss (table 3 , figure 3 ), but significantly affect the temperature distribution in the area of the tank.

\section{Notations}

$T$ - temperature, $\mathrm{K} ; \lambda$ - coefficient of thermal conductivity, $\mathrm{W} /(\mathrm{m} \cdot \mathrm{K}) ; \alpha-$ the heat transfer coefficient, $\mathrm{W} /\left(\mathrm{m}^{2} \cdot \mathrm{K}\right)$.

Indexes: ins - a layer of heat insulation; $\mathrm{g}$ - ground; oil - oil; $\mathrm{f}$ - foundation engineering structure; in - internal; ex - external; 1 - the inner surface of the tank insulation; 2 - the boundary between "shell of tank - ground"; 3 - the boundary between "soil - foundation engineering structure"; 4 - the boundary between "soil - environment"; 5 - the boundary between "soil - engineering structure"; 6 - the boundary between "foundation - the air inside the engineering structure" 7 - the boundary between "basement floor - the air inside the engineering structure"

\section{Acknowledgments}

The work was supported by the Russian President's grant (Scientific School project 7538.2016.8).

\section{References}

1. S. Korniyenko, Procedia Engineering 117, 1 (2015)

2. V.Yu. Polovnikov, E.V. Gubina, J. Eng. Phys. Thermophys. 87 (2014)

3. A.L. Garcia, Numerical methods for physics (Prentice Hall, New York, 2000)

4. V.Yu. Polovnikov, E.S. Glazyrin, EPJ Web Conf. 82 (2015)

5. J. N. Reddy An Introduction to Nonlinear Finite Element Analysis (Oxford University Press, New York, 2004) 